\title{
Lung functions among patients with pulmonary tuberculosis in Dar es Salaam - a cross-sectional study
}

\author{
Mohamed Manji ${ }^{1 *}$, Grace Shayo ${ }^{1}$, Simon Mamuya ${ }^{2}$, Rose Mpembeni ${ }^{3}$, Ahmed Jusabani $^{4}$ and Ferdinand Mugusi ${ }^{1}$
}

\begin{abstract}
Background: Approximately 40-60\% of patients remain sufferers of sequela of obstructive, restrictive or mixed patterns of lung disease despite treatment for pulmonary tuberculosis (PTB). The prevalence of these abnormalities in Tanzania remains unknown.
\end{abstract}

Methods: A descriptive cross-sectional study was carried out among 501 patients with PTB who had completed at least 20 weeks of treatment. These underwent spirometry and their lung functions were classified as normal or abnormal (obstructive, restrictive or mixed). Logistic regression models were used to explore factors associated with abnormal lung functions.

Results: Abnormal lung functions were present in 371 (74\%) patients. There were 210 (42\%) patients with obstructive, 65 (13\%) patients with restrictive and 96 (19\%) patients with mixed patterns respectively. Significant factors associated with abnormal lung functions included recurrent PTB (Adj OR 2.8, Cl 1.274 - 6.106), Human Immunodeficiency Virus (HIV) negative status (Adj OR 1.7, Cl 1.055 - 2.583), age more than 40 years (Adj OR 1.7, Cl 1.080 - 2.804) and male sex (Adj OR 1.7, Cl 1.123 - 2.614).

Conclusion: The prevalence of abnormal lung functions is high and it is associated with male sex, age older than 40 years, recurrent PTB and HIV negative status.

Keywords: Spirometry, TB sequlae, Obstruction, Restriction

\section{Background}

Tuberculosis (TB) is among the top infectious causes of death worldwide [1]. Patients with treated TB may remain lifelong sufferers of disabling sequelae of the disease which subsequently impair their quality of life [2]. Many studies have shown that partially treated pulmonary tuberculosis can result in airflow obstruction [3-7]. Studies with longer follow-up have revealed that a large percentage of patients with treated pulmonary tuberculosis show signs of permanent airflow obstruction or restrictive impairment [8-11]. Post tuberculosis pulmonary impairment, therefore has emerged as a distinct clinical entity [12].
With 170,000 reported TB cases in the year 2014, Tanzania ranked the $18^{\text {th }}$ among the 22 WHO high TB burdened countries in the world [13]. The prevalence of bacteriologically confirmed TB in Tanzania was 295 per 100,000 adults in the year 2010 [14]. Despite this high burden of TB, there is no formal evidence of post tuberculous pulmonary abnormalities from Tanzania. Factors associated with these complications or factors that may predict long term residual abnormalities in such patients has also been poorly addressed. This study was aimed at determining the prevalence and the factors associated with these abnormalities.

\section{Methods}

\section{Study design and population}

We conducted a health facility-based descriptive cross sectional study between July and December 2014 in Temeke municipality, the largest of three municipalities

\footnotetext{
${ }^{1}$ Department of Internal Medicine, Muhimbili University of Health and Allied

Sciences (MUHAS), P.O. Box 65001, Dar es Salaam, Tanzania

Full list of author information is available at the end of the article
} 
in Dar es Salaam city. Two busy TB clinics in this municipality, the Temeke municipal hospital and the Mbagala rangi tatu health centre, were chosen. The target population was patients with pulmonary tuberculosis (PTB), both sputum smear positive and smear negative TB regardless of their HIV status. Eligible patients were aged 18 years or older, had attended the clinic and completed at least 20 of the 24 weeks of anti TB treatment. Prior research has shown that peak lung function loss in patients with TB occurs within 6 months of diagnosis [8]. We enrolled patients who had completed 20 of the 24 weeks of anti TB treatment (i.e. 5 months), since most of these subjects would have achieved a microbiological cure, and that such timing would enable identification of sequel of disease without considering active disease. This timing was also reasonable in allowing data collection for a maximal number of subjects given that patients are discharged from the clinic at 6 months after which it would be difficult to access them. Participants were enrolled in a consecutive manner. The exclusion criteria were participants who had preexisting asthma or COPD, paraplegia, heart failure, stroke, extra pulmonary tuberculosis, contraindications to spirometry (e.g. recent surgery, myocardial infarction, vertigo, vomiting), spine deformities (kyphosis, scoliosis), chest deformities, and pregnancy.

A total of 501 participants were enrolled in the study (Fig. 1). All participants gave consent for participation. Ethical clearance for conducting the study was obtained from the Muhimbili University of Health and Allied Sciences (MUHAS) institutional review board.

\section{Data collection}

Evaluations were incorporated into routine TB clinic visits. A clinical record form (CRF) was used for data collection. A thorough history and physical examination was performed for each participant and recorded on the CRF. The modified Medical research council dyspnea scale was used to assess their functional status [15]. The patients TB02 treatment card was used to obtain other relevant information including duration on anti $\mathrm{TB}$ treatment, serostatus for HIV and whether the PTB was smear negative or positive for acid fast bacilli (AFB) at diagnosis. This information was filled in the CRF. A digital weighing scale (OMRON) was used to measure body weight in kilograms $(\mathrm{kg})$. Weight was measured in erect position wearing only light clothing and without shoes. Height was measured in centimeters using meter rods. Waist circumference was measured using a tape measure midway between the lower rib cage margin and the anterior superior iliac spine. Mid upper arm circumference (MUAC) was measured with a tape measure midway between the tip of the shoulder (the acromion) and the tip of the elbow (olecranon process).

This was followed by spirometry by means of the ndd EasyOne $^{\text {Th }}$ spirometer (manufactured by ndd Medizintechnik (Switzerland)). The EasyOne ${ }^{\mathrm{Tw}}$ spirometer complies with the 2005 ATS/ERS spirometry standards. The spirometer

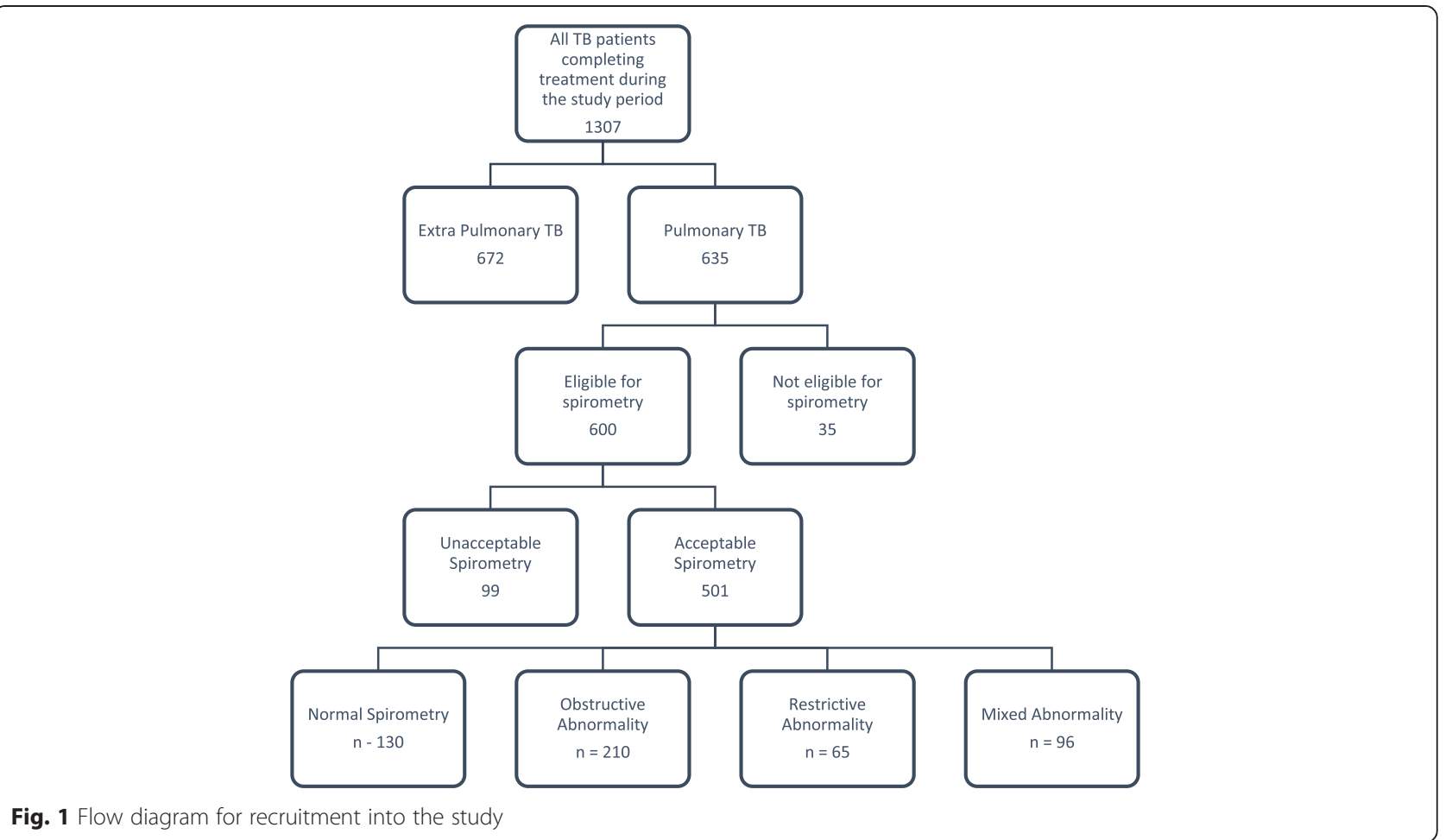


does not need daily calibration [16-18]. It has been used in several studies before both locally and internationally [19-22]. Thus pre testing of the tool was not performed. The device is portable and not affected by environmental conditions. Precautionary measures in using the spirometer included the use of disposable mouthpiece (spirette) per participant to avoid cross contamination. Spirometry was performed in a vacant area with open sunlight and face masks and gloves were used to protect the investigator/assistants.

The forced expiratory maneuvers, the within and between maneuver evaluation for acceptability as well as test result selection were in accordance with the ATS/ ERS guidelines [23]. Spirometry was performed in the standing position. The forced expiratory maneuvers were explained in local language by trained assistants (3 doctors and 1 nurse) to the participants before they underwent spirometry. Spirometry was performed without a nose clip owing to the results of a pilot study among 25 patients prior to this research that observed that patients were uncomfortable when nose clips were used during spirometry. Furthermore, a nose clip is recommended, but not a compulsory requirement for spirometry [23] and other studies have not shown significant differences in results among users and non-users of nose clips $[24,25]$. Disposable mouthpieces (spirettes) were discarded after individual use. Parameters measured included forced expiratory volume in one second (FEV1) and the forced vital capacity (FVC). The highest FEV1 and FVC from three acceptable maneuvers were used for further comparison and analysis. The FEV1: FVC\% was then calculated from these.

\section{Data analysis}

The lung functions were categorized into normal, obstruction, restriction and mixed patterns of lung disease according to the algorithm from the National Lung Health Education Program (NLHEP) [26].

The predicted values were derived from regression equations for healthy Tanzanian adults [22]. To compare the observed and predicted lung functions, we used the percentage of predicted values (the ratio of observed to predicted values times 100) for FVC (FVC \%) and FEV1 (FEV1\%). Severity for obstruction and restriction were graded according to Global Initiative for Chronic Obstructive Lung Disease (GOLD) [27] and the American Thoracic Society/European Respiratory Society (ATS/ ERS) task force recommendations [28] respectively.

Data was analyzed using SPSS (version 15.0) statistical software. Means \pm standard deviation $(\mathrm{SD})$ and proportions were calculated for continuous and categorical data respectively. Median and interquartile range (IQR) was used for non-normally distributed numerical data. The Chi square test and t-test were used to determine associations between variables. If more than $20 \%$ of the cells had an expected frequency of $<5$, Fischer's exact test was used instead.

Logistic regression was done to determine predictors of abnormal lung function. The dependent variable was lung function which was reported as normal or abnormal. The independent variables that were run in multivariate models were those that had a $\mathrm{p}$ value of $<0.2$ in univariate analysis. These included age, sex, level of education, Modified Medical Research Council Dyspnea Score (MMRC Score), smoking status, sputum smear status at diagnosis (positive or negative), TB episode number (first episode or recurrent), duration from symptoms to diagnosis of $\mathrm{TB}$, HIV serostatus (positive or negative) and CD4 counts. Statistically significance was achieved when $p<0.05$.

\section{Results}

\section{Study population}

There were a total of 501 participants in the study (Fig. 1). Males constituted $60.5 \%(303 / 501)$ of the study participants. More than $60 \%(326 / 501)$ of participants were aged 40 years or younger. Majority were married or cohabiting (52.5\%) (263/501), had attained primary level education (65.9\%) (330/501) and were domestic workers (34.1\%) (171/501). Approximately $29.3 \%$ (147/ 501 ) were ever smokers with a median of 2.5 pack years. With respect to their clinical characteristics, approximately $54.3 \%(272 / 501)$ had smear positive pulmonary TB and $90.1 \%(245 / 272)$ of these had converted to smear negative at 2 months of treatment. Majority (85\%) (426/501) of the patients had presented with a first episode of TB. The median time from first symptom presentation to TB diagnosis was 30 days. Approximately $30 \%(152 / 501)$ of the population was HIV coinfected. Approximately $46 \%(70 / 152)$ of the patients had CD4+ cell count $<200$ cells $/ \mu L$. Majority (81 \%) (407/501) had good functional scores (1 to 2 ) for dyspnea as reported by the MMRC score (Table 1). The mean FEV1, FVC and FEV1: FVC\% were $1.83 \pm 0.75$, $2.95 \pm 1.11$ and $63.02 \pm 17.99$ respectively.

\section{Prevalence and severity of abnormal lung functions}

The overall prevalence of lung function abnormalities was $74 \%$ (371/501). Majority was due to obstruction (42\%) (210/501) followed by mixed (19\%) (96/501) and restrictive (13\%) (65/501) abnormalities. Approximately $73 \%(48 / 65)$ of patients with restrictive dysfunction has mild to moderate severity. Approximately $79 \%$ (166/ 210) of patients with obstructive dysfunction had mild to moderate severity (Fig. 2).

\section{Factors associated with abnormal lung functions}

Patients who were aged 40 years or younger were less likely to present with abnormal lung functions (69.9\%) 
Table 1 Sociodemographic and clinical characteristics of participants

\begin{tabular}{|c|c|c|}
\hline Characteristics ( $\mathrm{N}=501)$ & Frequency & $\begin{array}{l}\text { Percent } \\
\text { (\%) }\end{array}$ \\
\hline \multicolumn{3}{|l|}{ Age Groups (years) } \\
\hline $18-30$ & 166 & 33.1 \\
\hline $31-40$ & 160 & 31.9 \\
\hline $41-50$ & 96 & 19.2 \\
\hline $51-60$ & 42 & 8.4 \\
\hline$>60$ & 37 & 7.4 \\
\hline \multicolumn{3}{|l|}{ Sex } \\
\hline Male & 303 & 60.5 \\
\hline Female & 198 & 39.5 \\
\hline \multicolumn{3}{|l|}{ Marital Status } \\
\hline Single & 169 & 33.7 \\
\hline Married/Cohabiting & 263 & 52.5 \\
\hline Divorced/Widowed & 69 & 13.8 \\
\hline \multicolumn{3}{|l|}{ Education } \\
\hline No Formal & 62 & 12.4 \\
\hline Primary & 330 & 65.9 \\
\hline Secondary & 84 & 16.8 \\
\hline Post-Secondary & 25 & 5.0 \\
\hline \multicolumn{3}{|l|}{ Occupation } \\
\hline Agriculture & 19 & 3.8 \\
\hline Domestic & 171 & 34.1 \\
\hline Industrial & 64 & 12.8 \\
\hline Office & 119 & 23.8 \\
\hline Other & 128 & 25.5 \\
\hline \multicolumn{3}{|l|}{ MMRC score } \\
\hline $1-2$ & 407 & 81.2 \\
\hline $3-5$ & 94 & 18.8 \\
\hline \multicolumn{3}{|l|}{ Cigarette smoking } \\
\hline Never smokers & 354 & 70.7 \\
\hline Ever Smokers & 147 & 29.3 \\
\hline Smoking Pack Years (Median (IQR)) & $2.5(5.3)$ & \\
\hline \multicolumn{3}{|l|}{ Smear for Acid Fast Bacilli } \\
\hline Positive & 272 & 54.3 \\
\hline Negative & 229 & 45.7 \\
\hline \multicolumn{3}{|l|}{$\begin{array}{l}\text { Time to Negative Sputum Conversion } \\
\text { (months) }(n=272)\end{array}$} \\
\hline Smear Negative at 2 Months & 245 & 90.1 \\
\hline Smear Positive at 2 Months & 27 & 9.9 \\
\hline \multicolumn{3}{|l|}{ TB Episode } \\
\hline First & 426 & 85.0 \\
\hline Recurrent & 75 & 15.0 \\
\hline
\end{tabular}

Table 1 Sociodemographic and clinical characteristics of participants (Continued)

\begin{tabular}{lll}
\hline Duration to TB diagnosis (months) & & \\
$\quad \leq 1$ Month & 275 & 54.9 \\
>1 Month & 226 & 45.1 \\
HIV Status & & \\
$\quad$ Positive & 152 & 30.3 \\
$\quad$ Negative & 349 & 69.7 \\
CD4 count $(n=152)$ & & \\
$<200$ & 70 & 46.2 \\
200-350 & 50 & 33.0 \\
$>350$ & 32 & 20.9 \\
\hline
\end{tabular}

MMRC Score Modified Medical Research Council Dyspnea Score, BMI Body Mass Index, IQR Interquartile range

compared to those older than 40 years $(81.7 \%), p=0.004$. Abnormal lung function was more prevalent among males $(78.9 \%)$ than among females $(66.7 \%)(p=0.002)$. However more males developed restrictive $(p=0.034)$ and mixed $(p<0.001)$ abnormalities while more females developed obstruction $(p<0.001)$ (Table 2). As far as clinical characteristics are concerned, higher MMRC scores were significantly associated with any abnormality ( $84 \%$ for scores $3-5$ vs $71.7 \%$ for score $1-2)(p=0.013)$. A similar finding was seen for mixed abnormalities $(p=0.009)$. However lower scores were significantly more associated with obstruction $(p=0.04)$. Patients who had more than 5 pack years of smoking had significantly higher obstructive abnormalities than those who had smoked for less than 5 pack years (73.3 \% vs. $41.9 \%)(p=0.005)$. Patients with recurrent TB were also more likely to have abnormal lung functions compared to those with a first episode of TB $(89.3 \%$ vs $71.4 \%)(p=0.001)$. Also HIV negative patients constituted significantly greater percentage of individuals with abnormal lung functions (77.1\%) compared to HIV infected patients $(67.1 \%)(p=0.019)$. This relationship was also true for mixed lung disease $(p=0.012)$. However obstructive dysfunction was more common in HIV infected $(66.7 \%)$ than in HIV negative patients $(52.4 \%)$ $(p=0.014)$ (Table 3).

In multivariate analysis significant predictors for any abnormality were age $>40$ years (Adj OR 1.740, CI 1.080 - 2.804), male sex (Adj OR 1.713, CI 1.123 - 2.614), TB recurence (Adj OR 2.789, CI 1.274 - 6.106) and HIV negative status (Adj OR 1.651, CI 1.055 - 2.583) (Table 4).

\section{Discussion}

The prevalence of abnormal lung functions of any type in this study was $74 \%$ and the prevalence of individual patterns of impairment was 42, 13 and $19 \%$ for obstructive, restrictive and mixed patterns of lung disease respectively. These findings indicate a huge burden of 


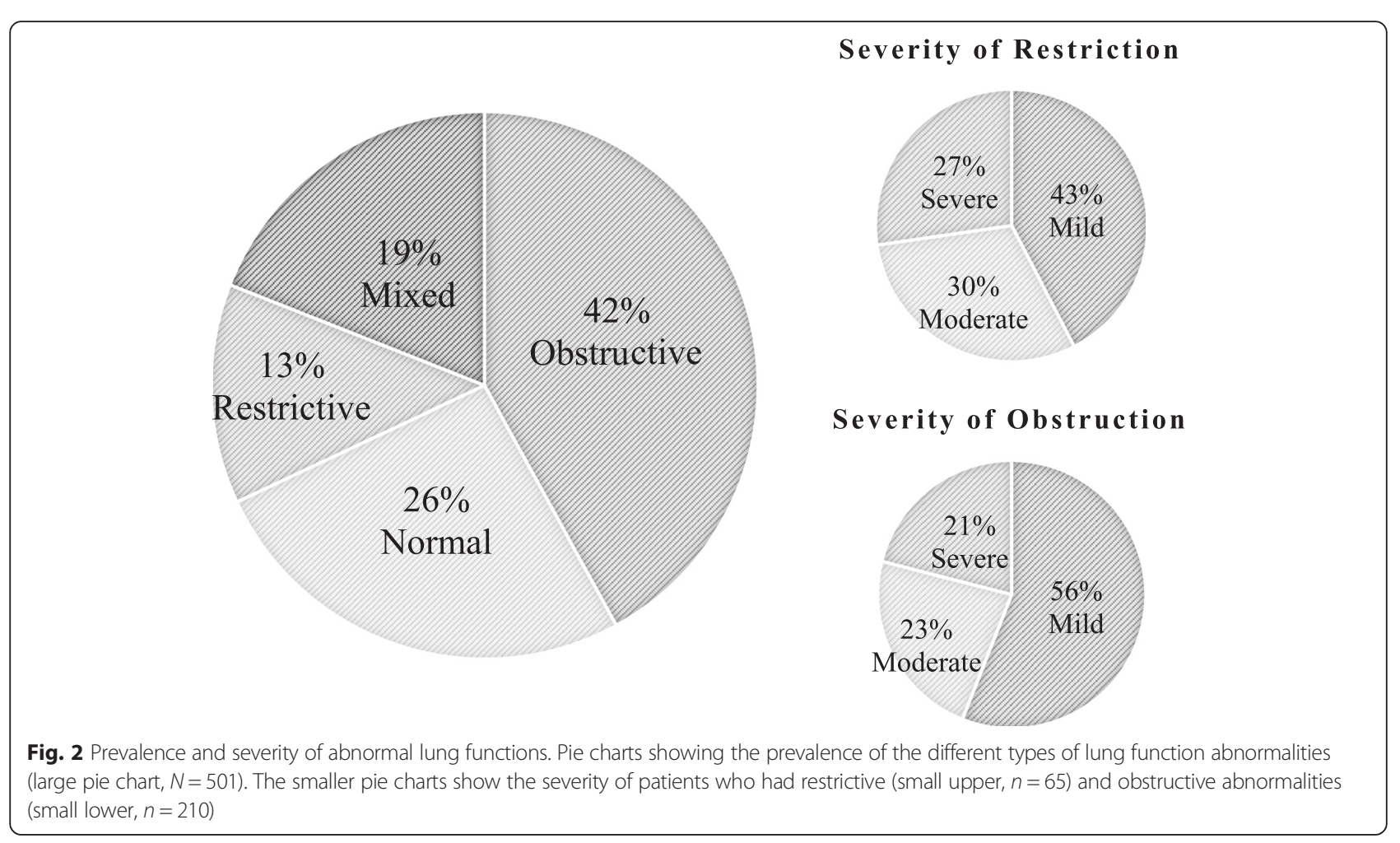

Table 2 Sociodemographic factors associated with abnormal lung functions

\begin{tabular}{|c|c|c|c|c|c|c|c|c|c|c|c|c|c|}
\hline \multirow{2}{*}{$\begin{array}{l}\text { Characteristics } \\
\text { Age groups (number, \%) }\end{array}$} & \multirow[t]{2}{*}{ Total } & \multicolumn{2}{|c|}{ Any Abnormality } & \multirow[t]{2}{*}{$P$} & \multicolumn{2}{|c|}{ Obstructive } & \multirow[t]{2}{*}{$P$} & \multicolumn{2}{|c|}{ Restrictive } & \multirow[t]{2}{*}{$P$} & \multicolumn{2}{|c|}{ Mixed } & \multirow[t]{2}{*}{$P$} \\
\hline & & & & & & & & & & & & & \\
\hline$\leq 40$ years & 326 & 228 & $69.9 \%$ & $0.004^{*}$ & 121 & $53.1 \%$ & $0.132^{*}$ & 46 & $20.2 \%$ & $0.163^{*}$ & 61 & $26.8 \%$ & $0.715^{*}$ \\
\hline$>40$ years & 175 & 143 & $81.7 \%$ & & 88 & $61.5 \%$ & & 20 & $14.0 \%$ & & 35 & $24.5 \%$ & \\
\hline \multicolumn{14}{|l|}{ Sex (number, \%) } \\
\hline Males & 303 & 239 & $78.9 \%$ & $0.003^{*}$ & 112 & $46.9 \%$ & $<0.001^{*}$ & 50 & $20.9 \%$ & $0.034^{*}$ & 77 & $32.2 \%$ & $<0.001^{*}$ \\
\hline Female & 198 & 132 & $66.7 \%$ & & 97 & $73.5 \%$ & & 16 & $12.1 \%$ & & 19 & $14.4 \%$ & \\
\hline \multicolumn{14}{|l|}{ Marital Status (number, \%) } \\
\hline Single & 169 & 120 & $71.0 \%$ & 0.432 & 64 & $53.3 \%$ & 0.679 & 23 & $19.2 \%$ & 0.723 & 33 & $27.5 \%$ & 0.874 \\
\hline Married/Cohabiting & 263 & 201 & $76.4 \%$ & & 115 & $57.2 \%$ & & 36 & $17.9 \%$ & & 50 & $24.9 \%$ & \\
\hline Divorced/W idowed & 69 & 50 & $72.5 \%$ & & 30 & $60.0 \%$ & & 7 & $14.0 \%$ & & 13 & $26.0 \%$ & \\
\hline \multicolumn{14}{|l|}{ Education (number, \%) } \\
\hline No Formal Education & 62 & 47 & $75.8 \%$ & 0.080 & 29 & $61.7 \%$ & 0.063 & 7 & $14.9 \%$ & 0.912 & 11 & $23.4 \%$ & 0.036 \\
\hline Primary Education & 330 & 249 & $75.5 \%$ & & 148 & $59.4 \%$ & & 45 & $18.1 \%$ & & 56 & $22.5 \%$ & \\
\hline Secondary Education & 84 & 62 & $73.8 \%$ & & 26 & $41.9 \%$ & & 11 & $17.7 \%$ & & 25 & $40.3 \%$ & \\
\hline Post-Secondary Education & 25 & 13 & $52.0 \%$ & & 6 & $46.2 \%$ & & 3 & $23.1 \%$ & & 4 & $30.8 \%$ & \\
\hline \multicolumn{14}{|l|}{ Occupation (number, \%) } \\
\hline Agriculture & 19 & 18 & $94.7 \%$ & 0.05 & 11 & $61.1 \%$ & 0.005 & 1 & $5.6 \%$ & 0.236 & 6 & $33.3 \%$ & 0.013 \\
\hline Domestic & 171 & 119 & $69.6 \%$ & & 81 & $68.1 \%$ & & 19 & $16.0 \%$ & & 19 & $16.0 \%$ & \\
\hline Industrial & 64 & 44 & $68.8 \%$ & & 16 & $36.4 \%$ & & 10 & $22.7 \%$ & & 18 & $40.9 \%$ & \\
\hline Office & 119 & 96 & $80.7 \%$ & & 53 & $55.2 \%$ & & 14 & $14.6 \%$ & & 29 & $30.2 \%$ & \\
\hline Other & 128 & 94 & $73.4 \%$ & & 48 & $51.1 \%$ & & 22 & $23.4 \%$ & & 24 & $25.5 \%$ & \\
\hline
\end{tabular}


Table 3 Clinical factors associated with abnormal lung functions

\begin{tabular}{|c|c|c|c|c|c|c|c|c|c|c|c|c|c|}
\hline \multirow{2}{*}{$\begin{array}{l}\text { Characteristics } \\
\text { MMRC score (number, \%) }\end{array}$} & \multirow[t]{2}{*}{ Total } & \multicolumn{2}{|c|}{ Any Abnormality } & \multirow[t]{2}{*}{$P$} & \multicolumn{2}{|c|}{ Obstructive } & \multirow[t]{2}{*}{$P$} & \multicolumn{2}{|c|}{ Restrictive } & \multicolumn{2}{|l|}{$P$} & \multirow[t]{2}{*}{ Mixed } & \multirow[t]{2}{*}{$P$} \\
\hline & & & & & & & & & & & & & \\
\hline $1-2$ & 407 & 292 & $71.7 \%$ & $0.013^{*}$ & 173 & $59.2 \%$ & $0.04^{*}$ & 53 & $18.2 \%$ & $0.868^{*}$ & 66 & $22.6 \%$ & 0.00 \\
\hline $3-5$ & 94 & 79 & $84 \%$ & & 36 & $45.6 \%$ & & 13 & $16.5 \%$ & & 30 & $38.0 \%$ & $9^{*}$ \\
\hline \multicolumn{14}{|l|}{ Cigarette smoking (number, \%) } \\
\hline Never smokers & 354 & 255 & $72.0 \%$ & $0.118^{*}$ & 151 & $59.2 \%$ & $0.114^{*}$ & 49 & $19.2 \%$ & $0.309^{*}$ & 55 & $21.6 \%$ & 0.00 \\
\hline Ever Smokers & 147 & 116 & $78.9 \%$ & & 58 & $50.0 \%$ & & 17 & $14.7 \%$ & & 41 & $35.3 \%$ & $7^{*}$ \\
\hline \multicolumn{14}{|c|}{ Smoking Pack Years (number, \%) $(n=147)$} \\
\hline$\leq 5$ & 107 & 86 & $80.4 \%$ & $0.5^{*}$ & 36 & $41.9 \%$ & $0.005^{*}$ & 16 & $18.6 \%$ & $0.068^{*}$ & 34 & $39.5 \%$ & 0.12 \\
\hline$>5$ & 40 & 30 & $75.0 \%$ & & 22 & $73.3 \%$ & & 1 & $3.3 \%$ & & 7 & $23.3 \%$ & $6^{*}$ \\
\hline \multicolumn{14}{|c|}{ Smear for Acid Fast Bacilli (number, \%) } \\
\hline Smear Positive & 272 & 198 & $72.8 \%$ & $0.54^{*}$ & 110 & $55.6 \%$ & $0.754^{*}$ & 31 & $15.7 \%$ & $0.278^{*}$ & 57 & $28.8 \%$ & 0.19 \\
\hline Smear Negative & 229 & 173 & $75.5 \%$ & & 99 & $57.2 \%$ & & 35 & $20.2 \%$ & & 39 & $22.5 \%$ & $2^{*}$ \\
\hline \multicolumn{14}{|c|}{ Time to Negative Sputum Conversion (number, \%) } \\
\hline Smear Positive at 2 Months & 27 & 19 & $70.4 \%$ & $0.82^{*}$ & 11 & $57.9 \%$ & $1.0^{*}$ & 3 & $15.8 \%$ & $1.0^{*}$ & & $26.3 \%$ & $1.0^{*}$ \\
\hline Smear Negative at 2 Months & 245 & 179 & $73.1 \%$ & & 99 & $55.3 \%$ & & 28 & $15.6 \%$ & & & $29.1 \%$ & \\
\hline \multicolumn{14}{|l|}{ TB Episode Number (number, \%) } \\
\hline First & 426 & 304 & $71.4 \%$ & $0.001^{*}$ & 171 & $56.3 \%$ & $1.0^{*}$ & 59 & $19.4 \%$ & $0.111^{*}$ & 74 & $24.3 \%$ & 0.16 \\
\hline Recurrent & 75 & 67 & $89.3 \%$ & & 38 & $56.7 \%$ & & 7 & $10.4 \%$ & & 22 & $32.8 \%$ & $6^{*}$ \\
\hline \multicolumn{14}{|c|}{ Duration to TB diagnosis (mo) (number, \%) } \\
\hline$\leq 1$ Month & 275 & 207 & 75.3 & $0.539^{*}$ & 117 & $56.5 \%$ & $1.0^{*}$ & 40 & $19.3 \%$ & $0.414^{*}$ & 50 & $24.2 \%$ & 0.40 \\
\hline$>1$ Month & 226 & 164 & 72.6 & & 92 & $56.1 \%$ & & 26 & $15.9 \%$ & & 46 & $28.0 \%$ & $6^{*}$ \\
\hline \multicolumn{14}{|l|}{ HIV Status (number, \%) } \\
\hline HIV Positive & 152 & 102 & $67.1 \%$ & $0.026^{*}$ & 68 & $66.7 \%$ & $0.014^{*}$ & 17 & $16.7 \%$ & $0.764^{*}$ & 17 & $16.7 \%$ & 0.01 \\
\hline HIV Negative & 349 & 269 & $77.1 \%$ & & 141 & $52.4 \%$ & & 49 & $18.2 \%$ & & 79 & $29.4 \%$ & $2^{*}$ \\
\hline CD4 count (Median (IQR)) & & 202.50 & 10) & & & $192.5(2$ & & & $200(156)$ & & & $260(167)$ & \\
\hline
\end{tabular}

* fishers exact, MMRC score Modified Medical Research Council Dyspnea score, BMI Body Mass Index, IQR Interquartile range

Table 4 Logistic regression analysis of sociodemographic and clinical parameters

\begin{tabular}{|c|c|c|c|c|c|c|c|}
\hline Characteristic $(n=501)$ & Comparison & OR & $95 \% \mathrm{Cl}$ & $P$ & Adj OR & $95 \% \mathrm{Cl}$ & $P$ \\
\hline Age $>40$ years & $\leq 40$ years & 1.921 & $1.224-3.014$ & 0.005 & 1.740 & $1.080-2.804$ & 0.023 \\
\hline Male & Female & 1.867 & $1.24-2.797$ & 0.002 & 1.713 & $1.123-2.614$ & 0.013 \\
\hline Any Formal Education & No Formal & 0.899 & $0.944-8.087$ & 0.736 & - & - & - \\
\hline MMRC score 3-5 & $\mathrm{MMRC} \leq 2$ & 2.074 & $1.147-3.752$ & 0.016 & 1.786 & $0.962-3.316$ & 0.066 \\
\hline Ever Smoker & Never smoker & 1.453 & $0.918-2.300$ & 0.111 & - & - & - \\
\hline Smear Positive TB & Smear Negative & 0.866 & $0.579-1.296$ & 0.484 & - & - & - \\
\hline Smear Positive at 2 months & Smear negative at 2 months & 0.876 & $.366-2.096$ & 0.766 & - & - & - \\
\hline TB recurrence (Any recurrence) & $1^{\text {st }}$ episode & 3.361 & $1.568-7.206$ & 0.002 & 2.789 & $1.274-6.106$ & 0.010 \\
\hline Duration to Diagnosis $>1$ month & $\leq 1$ months & 0.869 & $0.582-1.297$ & 0.492 & - & - & - \\
\hline HIV Negative & HIV Positive & 1.648 & $1.082-2.510$ & 0.020 & 1.651 & $1.055-2.583$ & 0.028 \\
\hline CD4 count $>350$ & $<350$ & 0.362 & $0.124-1.059$ & 0.064 & - & - & - \\
\hline
\end{tabular}


post treatment pulmonary function abnormalities in patients with pulmonary tuberculosis. It was also found that majority of patients with obstructive and restrictive abnormalities had mild to moderate severity. The findings of the present study are similar to those done elsewhere. For instance, in a study by Pasipanodya et al. (2007) in the USA, the prevalence of abnormal lung function of any type was $59 \%$ and the prevalence of individual subtypes of impairment for obstructive, restrictive and mixed were 15,31 and $13 \%$ respectively [29]. While the prevalence of pulmonary impairment was higher in our study, it suffices to note that pulmonary functions are abnormal in the majority of patients upon completion of chemotherapy. This has been a consistent finding in studies done in other parts of the world $[6,9,30]$.

A striking difference can be observed in the proportion of obstructive lung disease between the Pasipanodya study and the present study. The present study revealed a markedly higher proportion of patients who had obstructive lung disease (42\% vs $15 \%$ ). In some studies pulmonary infections (like childhood pneumonias, pneumocystis jirovecii, pertussis and measles) contribute up to a third of cases of obstructive airway disease [31-36]. Childhood pneumonias and measles are common in Tanzania. Other studies have found that the odds of developing obstructive disease may be even higher with TB than with smoking [19, 37, 38]. Poor socioeconomic status [39] and low birth weights [40] have also been linked with the development of obstructive impairments both of which are applicable to the Tanzanian setup. For example, $9.7 \%$ of the Tanzanian population are below the food and poverty line [41] and $13 \%$ of Tanzanian newborns are low birth weight [42]. Therefore, a predominance of obstructive sequelae after TB may not be so surprising in this part of the world.

We have shown that patients who presented with recurrent tuberculosis had a 2.8 fold higher likelihood of developing abnormal lung functions at the end of treatment than those with a first episode of TB. Considering that Tanzania is among the high burden countries, the burden of recurrent TB is also high. Studies in other parts of the world have also shown recurrent tuberculosis to be associated with adverse spirometric outcomes. In a population wide Korean study, Lee and colleagues showed that previous TB predicted almost 3 fold higher chance of developing obstructive lung disease [43]. Another South African study of approximately 27,000 miners showed incremental rise in lung function abnormalities with the number of TB episodes (18, 27 and $35 \%$ among first, second and third time sufferers of TB respectively) [8].

In the present study, it was found that HIV negative individuals had a 1.7 fold more likelihood of presenting with any form of lung impairment than were HIV infected patients. These findings can be explained by the fact that the mechanisms by which tuberculosis damages the lung depend extensively on cell mediated immune processes [44]. Many typical tuberculous changes may not be found in individuals who are HIV infected due to defects in their cell mediated immunity. These have been shown in studies comparing radiographic presentations of TB among HIV positive and negative individuals [45]. For example, HIV infected patients may not have typical upper lobe involvement or form typical cavities which confer significant structural alteration to the lung morphology [45]. As a result, it is likely that HIV positive patients end up with less spirometric abnormalities for lack of gross functional alteration due to relatively preserved lung parenchyma unlike their HIV negative counterparts.

The findings of this study warrant an active search among TB patients for these abnormalities. According to these results, practitioners in TB clinics can predict patients who may be at a higher risk for these impairments. Patients with recurrent tuberculosis, patients who are HIV negative, male patients and patients older than 40 years run the highest risk of these abnormalities. The tools to detect such abnormalities are fairly simple, rapid and not overly costly and there should not be a reason to miss this population who may require assistance beyond standard anti tuberculous therapy.

One may argue that these results actually make a case for an even more intensified and rapid detection of TB patients such that earlier treatment may offset the development of these sequelae. While this concept looks plausible in theory, the findings of the present study suggest otherwise. In a subgroup analysis of duration of symptoms to TB diagnosis and lung function, there was no significant difference among patients who were diagnosed and started treatment within 1 month against those who were diagnosed and started treatment later (Table 3). This relationship was also non-significant for obstructive, restrictive and mixed disease suggesting that simply having tuberculosis imparts a risk irrespective of how soon treatment is started.

The prevalence of these abnormalities among patients completing anti TB is alarmingly high. The morbidity and impairment in quality of life conferred by these sequelae is likely to be similarly high. While such data on long term morbidity is missing in Tanzania, literature from other parts of the world suggests that these sequelae confer a significant impact on everyday functioning and quality of life [2, 46-48]. In fact, some studies suggest greater morbidities from the sequelae rather than from the disease itself $[2,48]$. These non-communicable post tuberculous sequelae bring to light the often overlooked processes by which TB impacts quality of life. Tuberculosis therefore imposes an infectious and noninfectious burden to the healthcare infrastructure. While 
the infectious and microbiologic domain has received much attention in TB treatment, a lot is still left to be desired in the non-infectious sequela.

\section{Conclusions}

The magnitude of residual lung function abnormalities among patient with tuberculosis is high despite successful administration of anti TB medications. Important factors associated with abnormal lung functions include recurrent TB, HIV negative status, age more than 40 years and male sex. The findings of this study warrant an active search of these impairments among TB patients. Studies that look at the quality of life and socioeconomic impact of residual lung function abnormalities, screening strategies and treatment need to be conducted to supplement the findings of this study.

\section{Ethics approval and consent to participate}

Ethical clearance for conducting the study was obtained from the Muhimbili University of Health and Allied Sciences (MUHAS) institutional review board.

\section{Consent for publication \\ Not applicable.}

\section{Availability of data and materials}

The dataset supporting the conclusions of this article are stored with the Directorate of Research and Publications of the Muhimbili University of Health and Allied Sciences and can be made available upon request.

\section{Abbreviations \\ Adj: adjusted; ATS: American Thoracic Society; Cl: confidence interval; COPD: chronic obstructive pulmonary disease; CRF: clinical record form; DALYS: disability adjusted life years; ERS: European Respiratory Society; FEV1: forced expiratory volume in $1^{\text {st }}$ second; FVC: forced vital capacity; HIV: human immunodeficiency virus; IQR: interquartile range; MMRC: modified medical research council dyspnea score; MUAC: mid upper arm circumference; MUHAS: Muhimbili University of Health and Allied Sciences; OR: odd's ratio; PFT: pulmonary function test; PTB: pulmonary tuberculosis; SPSS: statistical package for social sciences; TB: tuberculosis.}

\section{Competing interests}

The authors declare that they have no competing interests.

\section{Authors' contributions}

MM, GS and FM were involved in designing the methodology, data analysis and discussion of the paper. MM, GS, FM, SM and AJ were involved in planning and technical aspects of data collection. MM, GS and RM conducted the data analysis. MM, GS and FM wrote the manuscript. All authors read and approved the final manuscript.

\section{Acknowledgements}

We extend our gratitude to the International Clinical, Operational and Health Services Research and Training Award (ICOHRTA) for their support. The authors would like to thank all the participants and their families for their cooperation and support. We would like to extend our appreciation to Ahmad Walji, Jaffer Lalji, Alihussein Molloo and Aliabbas Molloo who worked tirelessly during data collection. We would also like to thank Vasudev Uttamsingh and Sanjoy Basak for supplying the mouthpieces for this study. We would like to thank the staff of the Temeke Municipal Hospital and the Mbagala Rangi Tatu health centre TB clinics where the study was conducted.

\section{Author details}

'Department of Internal Medicine, Muhimbili University of Health and Allied Sciences (MUHAS), P.O. Box 65001, Dar es Salaam, Tanzania. ${ }^{2}$ Department of Environmental Occupational Health, Muhimbili University of Health and Allied Sciences (MUHAS), P.O. Box 65001, Dar es Salaam, Tanzania. ${ }^{3}$ Department of Epidemiology and Biostatistics, Muhimbili University of Health and Allied Sciences (MUHAS), P.O. Box 65001, Dar es Salaam, Tanzania. ${ }^{4}$ Department of Radiology, The Aga Khan Hospital, P.O Box 2289, Dar es Salaam, Tanzania.

Received: 10 November 2015 Accepted: 4 April 2016 Published online: 23 April 2016

\section{References}

1. WHO. The Global Burden of Disease 2004 Update. WHO. 2008.

2. Miller TL, McNabb SJN, Hilsenrath P, Pasipanodya J, Weis SE. Personal and societal health quality lost to tuberculosis. PLoS One. 2009;4:e5080.

3. Snider G, Doctor L, Demas T, Shaw A. Obstructive airway disease in patients with treated pulmonary tuberculosis. Am Rev Respir Dis. 1971;103(5):625-40.

4. Birath G, Caro J, Malmberg R, Simonsson BG. Airways obstruction in pulmonary tuberculosis. Scand J Respir Dis. 1966;47:27-36.

5. Lancaster JF, Tomashefski JF. Tuberculosis-a cause of emphysema. Am Rev Respir Dis. 1963;87:435-7.

6. Plit ML, Anderson R, Van Rensburg CE, Page-Shipp L, Blott JA, Fresen JL, Feldman C. Influence of antimicrobial chemotherapy on spirometric parameters and pro-inflammatory indices in severe pulmonary tuberculosis. Eur Respir J. 1998;12:351-6.

7. Simpson DG, Uschner M, Mcclement J. Respiratory function in pulmonary tuberculosis. Am Rev Respir Dis. 1963;87:1-16.

8. Hnizdo E, Singh T, Churchyard G. Chronic pulmonary function impairment caused by initial and recurrent pulmonary tuberculosis following treatment. Thorax. 2000;55:32-8.

9. Willcox PA, Ferguson AD. Chronic obstructive airways disease following treated pulmonary tuberculosis. Respir Med. 1989;83:195-8.

10. Krishna K, Bond S, Artvinli M, Reid KDG, McHardy GJR, Crofton JW. Pulmonary function in treated tuberculosis; a long-term follow-up. Am Rev Respir Dis. 1977;115:402-4.

11. Vargha G. Fifteen year follow-up of lung function in obstructive and non-obstructive pulmonary tuberculosis. Acta Med Hung. 1983;40:271-6.

12. Seaton A, LA Seaton D. Crofton and Douglass's Respiratory Disease. United Kingdom: Blackwell Science; 2002.

13. WHO. Global Tuberculosis Report 2015. 2015.

14. The First National Tuberculosis Prevalence Survey in the United Republic of Tanzania Final Report. 2013.

15. Stenton C. The MRC breathlessness scale. Occup Med (Lond). 2008;58:226-7.

16. Walters JAE, Wood-baker R, Walls J, Johns DP. Stability of the EasyOne ultrasonic spirometer for use in general practice. 2006. p. 306-10.

17. Skloot GS, Edwards NT, Enright PL. Four-Year Calibration Stability of the EasyOne Portable Spirometer. Respir Care. 2010;55:873-7.

18. Barr RG, Stemple KJ, Mesia-vela S, Basner C, Derk S, Henneberger P, Milton DK, Taveras B. Reproducibility and Validity of a Handheld Spirometer. Respir Care. 2008;53:433-41.

19. Hallal PC, Muin A, Lopez MV, Valdivia G, Talamo C, Pertuze J. Tuberculosis and airflow obstruction: evidence from the PLATINO study in Latin America . Eur Respir J. 2007;30:1180-5.

20. Carlsen HK, Gislason T, Benediktsdottir B, Kolbeinsson TB, Hauksdottir A, Thorsteinsson T, Briem H. A survey of early health effects of the Eyjafjallajökull 2010 eruption in Iceland: a population-based study. 2012.

21. Schirnhofer $L$, Firlei N. Using Targeted Spirometry to Reduce Non-Diagnosed Chronic Obstructive Pulmonary Disease. Respiration. 2011;81:476-82.

22. Knudsen TM, Mørkve ODD, Mfinanga S, Hardie JONA. Predictive equations for spirometric reference values in a healthy adult suburban population in Tanzania. Tanzan J Health Res. 2011;13:1-10.

23. Miller MR, Hankinson J, Brusasco V, Burgos F, Casaburi R, Coates A, Crapo R, Enright P, van der Grinten CPM, Gustafsson P, Jensen R, Johnson DC, Maclntyre N, McKay R, Navajas D, Pedersen OF, Pellegrino R, Viegi G, Wanger J. Standardisation of spirometry. Eur Respir J. 2005;26:319-38.

24. Chavasse R, Johnson P, Francis J, Balfour-Lynn I, Rosenthal M, Bush A. To clip or not to clip? Noseclips for spirometry. Eur Respir J. 2003;21:876-8. 
25. Newall C, McCauley T, Shakespeare J, Cooper B. Is it necessary to use a noseclip in the performance of spirometry using a wedge bellows device? Chron Respir Dis. 2007;4:53-7.

26. Ferguson $G$, Enright $P$, Buist $A$. Office spirometry for lung health assessment in adults: a consensus statement from the National Lung Health Education Program. Chest. 2000;117:1146-61.

27. Pauwels RA, Buist AS, Calverley PM, Jenkins CR, Hurd SS. Global strategy for the diagnosis, management, and prevention of chronic obstructive pulmonary disease. NHLBI/WHO Global Initiative for Chronic Obstructive Lung Disease (GOLD) Workshop summary. Am J Respir Crit Care Med. 2001; 163:1256-76.

28. Pellegrino R, Viegi G, Brusasco V, Crapo RO, Burgos F, Casaburi R, Coates A, Van Der Grinten CPM , Gustafsson P, Hankinson J, Jensen R, Johnson DC, Macintyre N, Mckay R, Miller MR, Navajas D, Pedersen OF, Wanger J. Interpretative strategies for lung function tests. Eur Respir J. 2005;26:948-968.

29. Pasipanodya JG, Miller TL, Vecino M, Munguia G, Garmon R, Bae S, Drewyer G. Weis SE. Pulmonary impairment after tuberculosis. Chest. 2007:131:1817-24.

30. Lee $\mathrm{JH}$, Chang $\mathrm{JH}$. Lung function in patients with chronic airflow obstruction due to tuberculous destroyed lung. Respir Med. 2003;97:1237-42.

31. Shoemark A, Ozerovitch L, Wilson R. Aetiology in adult patients with bronchiectasis. Respir Med. 2007;101:1163-70.

32. Konietzko NF, Carton RW, Leroy EP. Causes of death in patients with bronchiectasis. Am Rev Respir Dis. 1969;100:852-8.

33. Pasteur MC, Helliwell SM, Houghton SJ, Webb SC, Foweraker JE, Coulden RA, Flower CD, Bilton D, Keogan MT. An investigation into causative factors in patients with bronchiectasis. Am J Respir Crit Care Med. 2000;162(4 Pt 1): 1277-84.

34. Nicotra MB, Rivera M, Dale AM, Shepherd R, Carter R. Clinical, pathophysiologic and microbiologic characterization of bronchiectasis in an aging cohort. Chest. 1995;108:955-61.

35. Escombe AR, Moore DAJ, Gilman RH, Pan W, Navincopa M, Ticona E, Martínez C, Caviedes L, Sheen P, Gonzalez A, Noakes CJ, Friedland JS, Evans CA. The infectiousness of tuberculosis patients coinfected with HIV. PLoS Med. 2008;5:e188.

36. Calderon EJ, Rivero L, Respaldiza N, Morilla R, Montes-Cano MA, Friaza V, Munoz-Lobato F, Varela JM, Medrano FJ, de la Horra C. Systemic Inflammation in Patients with Chronic Obstructive Pulmonary Disease Who Are Colonized with Pneumocystis jiroveci. Clin Infect Dis. 2007;45:e17-9.

37. Ehrlich Rl, White N, Norman R, Laubscher R, Steyn K, Lombard C, Bradshaw D. Predictors of chronic bronchitis in South African adults. Int J Tuberc Lung Dis. 2004;8:369-76

38. Caballero A, Torres-Duque CA, Jaramillo C, Bolívar F, Sanabria F, Osorio P, Orduz C Guevara DP, Maldonado D. Prevalence of COPD in five Colombian cities situated at low, medium, and high altitude (PREPOCOL study). Chest. 2008;133:343-9.

39. Prescott $E$, Lange $P$, Vestbo J. Socioeconomic status, lung function and admission to hospital for COPD: results from the Copenhagen City Heart Study. Eur Respir J. 1999:13:1109.

40. Rona RJ, Gulliford MC, Chinn S. Effects of prematurity and intrauterine growth on respiratory health and lung function in childhood. BMJ. 1993;306:817-20.

41. National Bureau of Statistics: Tanzania in Figure 2014. Dar es Salaam. 2015.

42. UNICEF. Children and Women in Tanzania. 2010

43. Lee SW, Kim YS, Kim D-S, Oh Y-M, Lee S-D. The risk of obstructive lung disease by previous pulmonary tuberculosis in a country with intermediate burden of tuberculosis. J Korean Med Sci. 2011;26:268-73.

44. Cooper AM. Cell mediated immune responses in Tuberculosis. Annu Rev Immunol. 2009;27:393-422.

45. Swaminathan S, Narendran G, Menon PA, Padmapriyadarsini C, Arunkumar N, Sudharshanam NM, Kumar SR, Chandrasekhar S, Swaminathan S. Impact of HIV Infection on Radiographic Features in Patients with Pulmonary Tuberculosis. Indian J Chest Dis Allied Sci. 2007:49:133-6.

46. Weis SE, Miller TL, Hilsenrath PE, Moonan PK. Comprehensive cost description of tuberculosis care. Int J Tuberc Lung Dis. 2005:9:467.

47. Miller TL, Reading JA, Hilsenrath P, Weis SE. What are the costs of suspected but not reported tuberculosis? Ann Epidemiol. 2006;16:777-81.

48. Pasipanodya JG, McNabb SJ, Hilsenrath P, Bae S, Lykens K, Vecino E, Munguia G, Miller TL, Drewyer G, Weis SE. Pulmonary impairment after tuberculosis and its contribution to TB burden. BMC Public Health. 2010;10:259.

\section{Submit your next manuscript to BioMed Central and we will help you at every step:}

- We accept pre-submission inquiries

- Our selector tool helps you to find the most relevant journal

- We provide round the clock customer support

- Convenient online submission

- Thorough peer review

- Inclusion in PubMed and all major indexing services

- Maximum visibility for your research

Submit your manuscript at www.biomedcentral.com/submit

) Biomed Central 